\title{
Prof. John Longhurst und seine Frau Cherril bei Flugzeugabsturz tödlich verunglückt
}

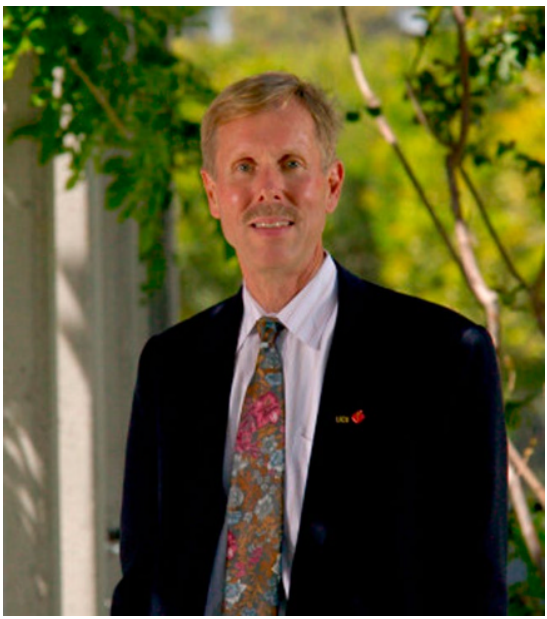

Mit großer Bestürzung und tiefer Trauer haben wir vom Tode von John Longhurst und seiner Frau Cherril erfahren. Er und seine Frau sind am frühen Morgen des 06.02. mit ihrer Cessna vom Gillespie Airport, Kalifornien gestartet. Kurz nach dem Start ist die Cessna wohl aufgrund eines technischen Defektes abgestürzt.

Unsere aufrichtige Anteilnahme gilt den Kindern des Paares, Dr. Chris Longhurst, Jenny Cretu und Dana Holve.

Prof. Longhurst war nominiert als Kongresspräsident des ICMART-iSAMS 2018, den die DÄGfA gemeinsam mit dem ICMART, der LMU München und iSAMS im September ausrichten wird.
Die Nachricht vom Ableben von John und seiner lieben Frau Cherril trifft uns schwer, dennoch werden wir diesen Kongress im Sinne von John durchführen.

John Longhurst war Kardiologe und spezialisiert auf Prävention und Behandlung kardiovaskulärer Erkrankungen. Er war vor seiner Emeritierung Direktor des Departments für Innere Medizin sowie Professor am Department für Physiologie, Biophysik und Pharmakologie an der University of California, Irvine. Von 2003 bis 2014 war er Direktor des Susan Samueli Centers für Integrative Medizin.

John war ein international anerkannter und hochdekorierter Experte auf dem Gebiet der Kardiologie mit dem Schwerpunkt der peripheren und autonomen Regulation des kardiovaskulären Systems. Seit 1978 wurden seine Forschungsprojekte kontinuierlich durch das NIH gefördert. In diesem Kontext hat er die wesentlichen wissenschaftlichen Grundlagen für das Verständnis der Akupunktur in der Behandlung der Hypertonie gelegt. Er war ein begehrter Berater in vielen nationalen und internationalen Gremien, sein Lebenswerk umfasst über 190 Originalpublikationen und 63 Übersichtsartikel und Buchkapitel.

John war einer der ersten anerkannten Schulmediziner, der sich kontinuierlich für die Akupunktur und integrative Medizin einsetzte.

Er war mit seiner liebenswerten Frau Cherril erst vor knapp einem Jahr auf der Jahrestagung der DÄG $f$ A in Bad Nauheim zu Gast. Sein Hauptvortrag über die peripheren und zentralen Mechanismen der autonomen kardiovaskulären Regulation durch Akupunktur zeigte klar und deutlich das Potenzial der Akupunktur in der Kardiologie. Seine ruhige, besonnene und verbindliche Art, seine Offenheit für die Akupunktur und integrative Medizin und seine außergewöhnliche Kompetenz haben uns alle beeindruckt.

Wir alle verlieren mit John einen großen Fürsprecher für die Akupunktur. Sein scharfer Verstand, seine Offenheit im Geiste und seine Integrität des Handelns waren vorbildlich. Seine große Leidenschaft war seine Familie und das Erleben der Natur auf unzähligen Wanderungen und Exkursionen mit Cherril.

Wir werden John und Cherril ein ehrendes Andenken bewahren. Mögen sie in Frieden ruhen.

Dominik Irnich

im Namen des Vorstandes der DÄGfA und im Namen der Co-Chairs des ICMARTiSAMS 2018 